\title{
Cephalometric Evaluation of Class III Malocclusion Cases with Different Vertical Facial Development
}

\author{
Barçın Eröz Dilaverr', Büșra Beșer ${ }^{1}$, Özlem Çelebi Erdivanlı², Engin Dursun² \\ 1 Department of Orthodontics, Faculty of Dentistry, Recep Tayyip Erdogan University, Rize, Turkey \\ 2 Department of Otolaryngology, Faculty of Medicine, Recep Tayyip Erdogan University, Rize, Turkey \\ Barçın Eröz Dilaver, ORCID: 0000-0003-2811-7166 \\ Büşra Beşer, ORCID: 0000-0002-7280-0168 \\ Özlem Çelebi Erdivanl, ORCID: 0000-0001-9245-1551 \\ Engin Dursun, ORCID: 0000-0002-2070-8677
}

\begin{abstract}
Objective: The purpose of the present study was to investigate the relationship between vertical facial development and angular and linear measurements of the face.

Methods: Pretreatment cephalometric radiographs of subjects with class III malocclusion were divided into three groups according to vertical facial development as low, normal and high angle. Nine angular, three dimensional and one ratio measurements were performed with the analysis program (AudaxCeph ver. 5.2.0.3610, Audax Slovenia) on the cephalometric radiographs and compared between the vertical growth groups.
\end{abstract}

Results: There was a significant negative correlation between the Sella-Nasion/Gonion-Menton (SN-GoMe) and Saddle-Nasion-A (SNA), Saddle-Nasion-B (SNB), Incisal
Mandibular Plane Angle (IMPA) and Jarabak ratio measurements, whereas a significant positive correlation was found between the SN-GoMe and the Gonial and Saddle measurements.

Conclusion: According to the results of the present study, we determined that anterior and posterior development of the face decreases with the increase in the vertical direction of the face. Also, an increase in vertical direction angles including Gonial and Saddle angles significantly correlated with the increase in SN-GoMe angle. Since vertical growth problems can cause complicated and long orthodontic treatment, factors that may affect vertical growth should be addressed, such as mouth breathing.

Keywords: Maxillofacial development, malocclusion, angle class III, vertical dimension, cephalometry. 


\section{Introduction}

Many factors can influence the development of the craniofacial complex and occlusion. Environmental factors such as habits and trauma can cause changes in the phenotype along with the genetic structure. Moss and Salentijn ${ }^{[1]} \mathrm{ex}^{-}$ plained skeletal growth and development with a functional matrix hypothesis, which proposes that the origin, development and maintenance of all skeletal units are secondary, compensatory and mechanically obligatory responses to temporally and operationally prior demands of related functional matrices. Ranly ${ }^{[2]}$ also advocated the common effect of genetic transition and functional matrix on growth and development. Another well-known theory regarding skeletal growth was Wolf's law, which advocates that mechanical loads can affect bone architecture in living beings, ${ }^{[3]}$ however, there are also different theories of growth and development. ${ }^{[4-6]}$

Facial aesthetics and balance can be affected by many skeletal units. The effects of vertical growth on the nasomaxillar complex, alveolar processes and mandible were investigated in some studies ${ }^{[7-9]}$ and it was shown that the actual increase in bone volume in the growth of the face occurs in sutures, alveolar processes and mandibular condyles. ${ }^{[10]}$

In 1981, Harvold et al. ${ }^{[11]}$ showed that mouth breathing due to experimentally developed nasal obstruction in healthy monkeys was followed by class III malocclusion. Bresolin et al. ${ }^{[12]}$ investigated the effects of respiratory functions on the growth and development of dentofacial structures. He concluded that mouth breathers had longer faces with narrower maxillae and retrognathic jaws. Zheng et al. ${ }^{[13]}$ found that individuals with mouth breathing had an increase in the mandibular plane angle and anterior height while there was a decrease in the posterior height.

The purpose of the present study was to investigate the relationship between vertical facial development and angular and linear measurements of the face.

\section{Materials and Methods}

Ethics committee approval for the present study was obtained from the non-invasive clinical research ethics committee of Recep Tayyip Erdogan University (No: 40465587-17). This retrospective study was conducted on cephalometric radiographs of 50 subjects with class III malocclusion obtained from the archives of the Department of Orthodontics, Faculty of Dentistry, Recep Tayyip Erdogan University. Demographic data of the subjects is shown in Table 1. Inclusion criteria of the subjects were as follows:

- Subjects should have negative overjet,

- A-Nasion-B (ANB) angle should be 0 or less,

- Wits value should be $0 \mathrm{~mm}$ or smaller,

- The patient should have no craniofacial syndrome, no cleft lip or cleft palate.

The subjects were divided into three groups according to the Sella-Nasion/Gonion-Menton (SN-GoMe) angle as follows; Low angle: 12 cases with reduced vertical facial development (SN-GoMe<31), Linear angle: 22 cases with normal facial development and High angle: 16 cases with increased vertical facial development (SN-GoMe $>37)$. The normal value of $\mathrm{SN}-\mathrm{GoMe}$ was determined by staying within the standard deviation range in Riedel's study. ${ }^{[14]}$

Radiographs of the subjects were taken in the natural head posture with the same cephalostat (Planmeca Promax Ceph X-ray Machine, Helsinki, Finland). Lateral cephalometric radiographs were taken with the teeth in centric occlusion, the lips at rest and the Frankfurt plane parallel to the ground.

Nine angular, three dimensional and one ratio measurements were performed on the cephalometric radiographs obtained with an analysis program (AudaxCeph ver. 5.2.0.3610, Audax, Slovenia). Fifteen radiographs were randomly selected to determine the errors associated with the cephalometric measurements. The radiographs were

Table 1. Demographic data of the subjects.

\begin{tabular}{lcccc} 
& Group I (High Angle) & Group II (Normal) & Group III (Low Angle) & p \\
\cline { 2 - 5 } Age $($ mean \pm SD) & $12.56 \pm 1.7$ & $12.27 \pm 1.7$ & $11.91 \pm 2$ & 0.65 \\
Sex (F/M) & $10 / 6$ & $16 / 6$ & $7 / 5$ & 0.67 \\
\hline
\end{tabular}

F/M: Female/Male, SD: standard deviation. 
reevaluated and measured by an orthodontist and there was no significant difference between the first and second measurements according to the statistical comparison (Table 2). Cephalometric measurements that were performed in the present study are shown Figure 1.

Figure 1. Cephalometric landmarks and measurements.

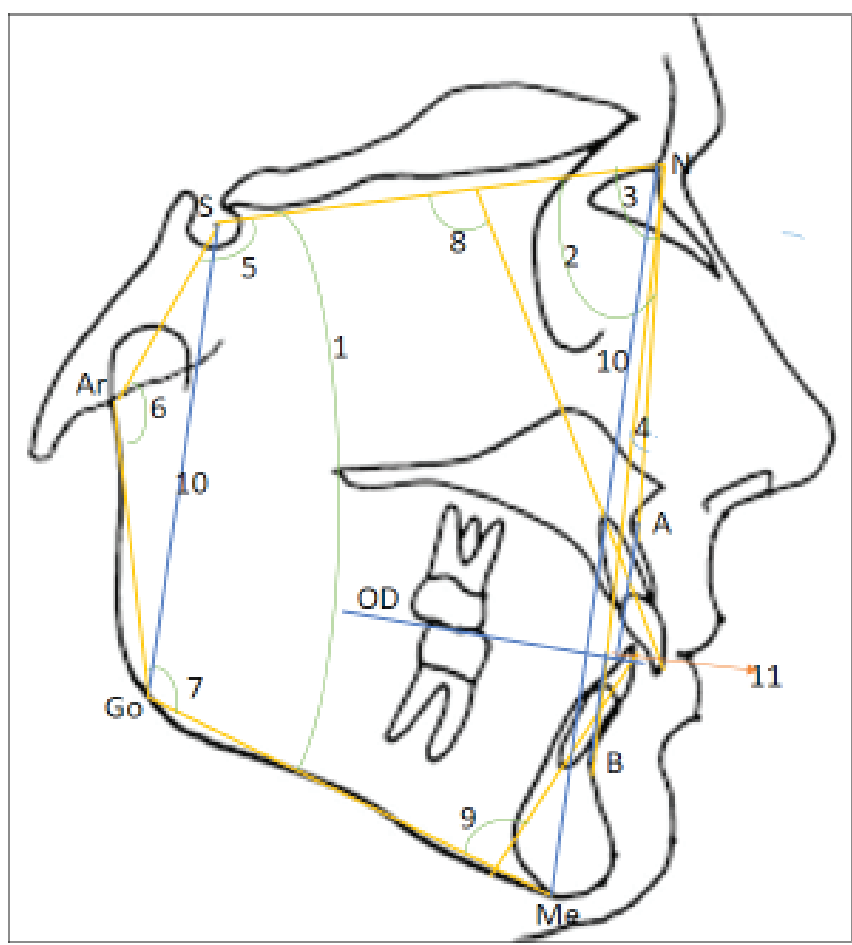

1-Sella-Nasion/Gonion-Menton (SN-GoMe) angle, 2-Saddle-Nasion-A (SNA) angle, 3-Saddle-Nasion-B (SNB) angle, 4-A-Nasion-B (ANB) angle, 5-Saddle angle, 6-Articular angle, 7-Gonial angle, 8-Upper 1-Sella Nasion (U1-SN) angle, 9-Incisal Mandibular Plane Angle (IMPA), 10-Jarabak ratio, 11-Wits value.

\section{Angular Measurements}

- SN-GoMe: The angle between the line connecting Sella and Nasion points $(\mathrm{S}-\mathrm{N})$ and the mandibular plane. This angle is used to determine vertical direction development.

- SNA: The angle between the S-N and Nasion-A (N-A) lines. The SNA angle determines the position of the upper jaw relative to the cranium.

- SNB: The angle between the S-N and Nasion-B (N-B) lines. The SNB angle determines the position of the mandible relative to the cranium.

\begin{tabular}{lccc} 
Table 2. Reproducibility data of the measurements. & \\
\hline Parameters & X1 & X2 & $r$ \\
\hline SN-GoMe angle & 34.89 & 34.66 & $0.995^{*}$ \\
SNA angle & 76.37 & 76.40 & $0.985^{*}$ \\
SNB angle & 79.16 & 79.33 & $0.988^{*}$ \\
ANB angle & -2.79 & -2.68 & $0.990^{*}$ \\
Wits value & -6.08 & -5.96 & $0.982^{*}$ \\
Saddle angle & 123.06 & 123.22 & $0.975^{*}$ \\
Articular angle & 144.39 & 144.29 & $0.936^{*}$ \\
Gonial angle & 127.03 & 127.11 & $0.985^{*}$ \\
Jarabak ratio & 63.09 & 63.02 & $0.969^{*}$ \\
U1-SN angle & 106.19 & 105.98 & $0.930^{*}$ \\
IMPA angle & 89.91 & 89.86 & $0.993^{*}$ \\
\hline
\end{tabular}

ANB: A-Nasion-B, IMPA: Incisal Mandibular Plane Angle, SNA: Saddle-Nasion-A, SNB: Saddle-Nasion-B, SN-GoMe: Sella-Nasion/Gonion-Menton, X1: Mean values of the first measurements, X2: Mean values of the second measurements, U1-SN: Upper 1-Sella Nasion.

$* p<0.001$

- ANB: The angle between the N-B and N-A lines. It shows the severity of the anterior-posterior anomaly between the lower and upper jaw.

- Saddle: The angle between the S-N and Sella-Articular (S-Ar) lines.

- Articular: The angle between S-Ar and Articular- Gonion (Ar-Go) lines.

- Gonial: The angle between Ar-Go line and the mandibular plane.

- U1SN: The angle of intersection of the long axis of the upper incisor and the S-N line.

- IMPA (Incisor mandibular plane angle): The angle between the mandibular plane and the long axis of the lower incisor.

\section{Dimensional Measurements}

- Wits value: The distance between points A and B on the maxilla and mandible, respectively, onto the occlusal plane (mm) 
- S-Go: Linear distance between Sella and Gonion (mm)

- N-Me: Linear distance between Nasion and Menton $(\mathrm{mm})$

\section{Ratio Measurement}

- Jarabak ratio: The ratio is obtained by the formula of posterior facial height/anterior facial height x 100 [(S-Go/N-Me) x100]

\section{Statistical Analysis}

Statistical Package for the Social Sciences (v. 22; SPSS Inc.; Chicago; IL; USA) was used for statistical analysis. Data are shown as mean \pm standard deviation. Categorical variables were compared using chi-square test. One-Way ANOVA and Pearson's correlation coefficient tests were utilized to analyze skeletal measurements. A p-value less than 0.05 was considered statistically significant.

\section{Results}

There was no significant difference between the groups in terms of age and gender. SNA, SNB, Saddle, Gonial, Jarabak ratio, and IMPA measurements were significantly different among the groups (Table 3). There was a significant negative correlation between the Sella- Nasion/Go-
nion-Menton (SN-GoMe) and Saddle-Nasion-A (SNA), Saddle-Nasion-B (SNB), Incisal Mandibular Plane Angle (IMPA) and Jarabak ratio measurements. In contrast, a significant positive correlation was found between the SNGoMe and the Gonial and Saddle measurements (Table 4).

\begin{tabular}{|c|c|}
\hline & SN-GoMe \\
\hline SNA angle & $-.578 *$ \\
\hline SNB angle & $-.680 *$ \\
\hline Saddle angle & $.429 *$ \\
\hline Gonial angle & $.398^{*}$ \\
\hline Jarabak ratio & $-.862 *$ \\
\hline IMPA angle & $-.387^{*}$ \\
\hline
\end{tabular}

IMPA: Incisal Mandibular Plane Angle, SNA: Saddle-Nasion-A, SNB: Saddle-Nasion-B, SN-GoMe: Sella-Nasion/Gonion-Menton.

* $p<0.01$

Table 3. Comparison of mean values of measurements among the groups.

\begin{tabular}{|c|c|c|c|c|}
\hline & Low angle & Linear angle & High angle & $p$ \\
\hline SNA angle & $79.50 \pm 3.02$ & $76.47 \pm 3.66$ & $74.40 \pm 3.89$ & .002 \\
\hline SNB angle & $83.00 \pm 3.72$ & $79.00 \pm 3.27$ & $77.00 \pm 4.27$ & .000 \\
\hline ANB angle & $-3.50 \pm 2.32$ & $-2.52 \pm 1.62$ & $2.60 \pm 1.86$ & .340 \\
\hline Wits value & $-6.25 \pm 2.98$ & $-5.58 \pm 2.93$ & $6.42 \pm 3.95$ & .734 \\
\hline Saddle angle & $118.50 \pm 4.62$ & $124.63 \pm 5.06$ & $124.37 \pm 6.83$ & .011 \\
\hline Articular angle & $142.87 \pm 10.19$ & $143.97 \pm 7.48$ & $145.67 \pm 8.35$ & .648 \\
\hline Gonial angle & $124.33 \pm 5.94$ & $125,41 \pm 5.72$ & $130.10 \pm 5.66$ & .012 \\
\hline Jarabak ratio & $68.27 \pm 2.82$ & $63.41 \pm 1,42$ & $59.68 \pm 2.80$ & .000 \\
\hline U1-SN angle & $107.54 \pm 5.88$ & $108.13 \pm 5.99$ & $103.62 \pm 7.68$ & .096 \\
\hline IMPA angle & $92.75 \pm 5.36$ & $90.80 \pm 5.33$ & $87.40 \pm 6.18$ & .034 \\
\hline
\end{tabular}

ANB: A-Nasion-B, IMPA: Incisal Mandibular Plane Angle, SD: Standart deviation, SNA: Saddle-Nasion-A, SNB: Saddle-Nasion-B, SN-GoMe: Sella-Nasion/Gonion-Menton, U1-SN: Upper 1-Sella Nasion. 


\section{Discussion}

Development of craniofacial structures of individuals may vary depending on nasal or oral breathing, which is an important issue for an orthodontist since it affects the planning and course of orthodontic treatment. Mouth breathing as a result of environmental factors such as allergic rhinitis and adenoid hypertrophy may cause increased vertical facial development. ${ }^{[16,17]}$ Children with mouth breathing were reported to show more vertical growth than children with nasal breathing. ${ }^{[18,19]}$ It has been reported that allergic diseases, which can be considered among the causes of mouth breathing, affect $15-20 \%$ of the population and the most common cause of chronic nasal obstruction in children is allergy. ${ }^{[20,21]}$

In the present study, a significant difference was demonstrated among the groups in terms of SNA, SNB, IMPA, Gonial, Saddle angles and Jarabak ratio. Also, SNA, SNB, IMPA, Gonial, Saddle angles and Jarabak ratio showed a significant correlation with SN-GoMe. Similar correlations between different skeletal parameters have also been reported in the literature. ${ }^{[20-22]}$ We found a negative correlation between vertical growth pattern and Jarabak ratio in our study. This result is in concordance with the study conducted by Asad and Naeem. ${ }^{[20]}$ Regarding the sagittal relationship, there was a negative correlation between SN-GoMe and SNB angles in the present study. Some studies showed similar findings that the mandible is in a more retroclined position with an increased SN-GoMe angle in mouth breathing children. ${ }^{[23-25]}$

Zheng et al. ${ }^{[13]}$ demonstrated that an increase in vertical angle causes an increase in anterior height with a decrease in posterior height due to the decrease in Jarabak ratio. The findings of this study were compatible with our study. We also found that the increase in the vertical direction encourages clockwise rotation, which causes facial imbalances, joint problems and more complicated orthodontic treatments.
Isaacson et al. ${ }^{[26]}$ and Ucar and Uysal ${ }^{[27]}$ stated that the increase in vertical direction causes a decrease in the development of anterior-posterior angles, which is compatible with the findings of the present study. Also, while SNGoMe increased, anterior-posterior angles such as SNA, SNB and IMPA decreased. The increase in vertical growth correlated negatively with the growth of the jaw in the anterior and posterior directions.

\section{Conclusion}

According to the results of the present study, we determined that anterior and posterior development of the face decreases with the increase in the vertical direction of the face. Also, an increase in vertical direction angles including Gonial and Saddle angles significantly correlated with the increase in SN-GoMe angle. Since vertical growth problems can cause complicated and long orthodontic treatment, factors that may affect vertical growth should be addressed, such as mouth breathing.

\section{Acknowledgments: None.}

Ethics Committee Approval: The study protocol was approved by the non-invasive clinical research ethics committee of Recep Tayyip Erdogan University (No: 4046558717).

Informed Consent: Written informed consent was not obtained due to the retrospective nature of the study.

Author Contributions: Designing the study - B.E.D.; Collecting the data - B.B., Ö.E.Ç., E.D.; Analysing the data B.E.D., B.B.; Writing the manuscript - B.E.D., B.B.; Confirming the accuracy of the data and the analyses - Ö.E.Ç., E.D.

Conflict of Interest: The authors have no conflicts of interest to declare.

Financial Disclosure: The authors declare that this study has received no financial support. 


\section{References}

1. Moss ML, Salentijn L. The primary role of functional matrices in facial growth. Am J Orthod 1969;55:566-77.

2. Ranly DM. Craniofacial growth. Dent Clin North Am 2000;44:457-70.

3. Frost HM. A 2003 update of bone physiology and Wolff's Law for clinicians. Angle Orthod 2004;74:3-15.

4. Björk A. The use of metallic implants in the study of facial growth in children: method and application. Am J Phys Anthropol 1968;29:243-54.

5. Björk A, Skieller V. Growth of the maxilla in three dimensions as revealed radiographically by the implant method. Br J Orthod 1977;4:5364.

6. Björk A, Skieller V. Facial development and tooth eruption. An implant study at the age of puberty. Am J Orthod 1972;62:339-83.

7. Enlow DH, Harris DB. Study of the Postnatal Growth of the Human Mandible. Am J Orthod 1964;50:25-50.

8. Opdebeeck H, Bell WH. The short face syndrome. Am J Orthod 1978;73:499-511.

9. Schudy FF. Vertical Growth Versus Anteroposterior Growth As Related To Function And Treatment. Angle Orthod 1964;34:75-93.

10. Brodie AG. On the growth pattern of the human head. From the third month to the eighth year of life. Am J Anat 1941;68:209-62.

11. Harvold EP, Tomer BS, Vargervik K, Chierici G. Primate experiments on oral respiration. Am J Orthod 1981;79:359-72.

12. Bresolin D, Shapiro PA, Shapiro GG, Chapko MK, Dassel S. Mouth breathing in allergic children: its relationship to dentofacial development. Am J Orthod 1983;83:334-40.

13. Zheng W, Zhang X, Dong J, He J. Facial morphological characteristics of mouth breathers vs. nasal breathers: A systematic review and meta-analysis of lateral cephalometric data. Exp Ther Med 2020;19:3738-50.

14. Riedel RA. The relation of maxillary structures to cranium in malocclusion and in normal occlusion. Angle Orthod 1952;22:142-5.

15. Nielsen IL. Vertical malocclusions: etiology, development, diagnosis and some aspects of treatment. Angle Orthod 1991;61:247-60.

16. Ceylan I, Baydas B, Erdem A. The investigation of the effects of mouth breathing on transverse and vertical facial growth. [Article in Turkish] Atatürk Üniv Diş Hek Fak Derg 1995;5:39-46.
17. Trask GM, Shapiro GG, Shapiro PA. The effects of perennial allergic rhinitis on dental and skeletal development: a comparison of sibling pairs. Am J Orthod Dentofacial Orthop 1987;92:286-93.

18. Yang K, Zeng X, Yu M. A study on the difference of craniofacial morphology between oral and nasal breathing children. Zhonghua Kou Qiang Yi Xue Za Zhi 2002;37:385-7.

19. Chung Leng Muñoz I, Beltri Orta P. Comparison of cephalometric patterns in mouth breathing and nose breathing children. Int J Pediatr Otorhinolaryngol 2014;78:1167-72.

20. Asad S, Naeem S. CORRELATION BETWEEN VARIOUS VERTICAL DYSPLASIA ASSESSMENT PARAMETERS. POJ 2009;1:28-33.

21. Bahrou S, Hasan AA, Khalil F. Facial proportions in different mandibular rotations in class I individuals. Int Arab J Dent 2014;5:9-18.

22. Rizwan M, Mascarenhas R, Husain A. Reliability of the Existing Vertical Dysplasia Indicators In Assessing A Definitive Growth Pattern. Rev Latinoam Ortod Odontopediatría 2011;1-5. (Published: December 16, 2011)

23. Souki BQ, Lopes PB, Pereira TB, Franco LP, Becker HM, Oliveira DD. Mouth breathing children and cephalometric pattern: does the stage of dental development matter? Int J Pediatr Otorhinolaryngol 2012;76:83741.

24. Freeman GL, Johnson S. Allergic Diseases In Adolescents: 1. Description of Survey; Prevalence of Allergy. Am J Dis Child 1964;107:549-59.

25. Juliano ML, Machado MA, Carvalho LB, Prado LB, do Prado GF. Mouth breathing children have cephalometric patterns similar to those of adult patients with obstructive sleep apnea syndrome. Arq Neuropsiquiatr 2009;67:860-5.

26. Isaacson JR, Isaacson RJ, Speidel TM, Worms FW. Extreme variation in vertical facial growth and associated variation in skeletal and dental relations. Angle Orthod 1971;41:219-29.

27. Ucar FI, Uysal T. Orofacial airway dimensions in subjects with Class I malocclusion and different growth patterns. Angle Orthod 2011;81:4608.

This is an open access article distributed under the terms of the Creative Commons Attribution-NonCommercial-NoDerivs 3.0 Unported (CC BY- NC-ND3.0) Licence (http://creativecommons.org/licenses/by-nc-nd/3.0/) which permits unrestricted noncommercial use, distribution, and reproduction in any medium, provided the original work is properly cited.

Please cite this article as: Eröz Dilaver B, Beşer B, Çelebi Erdivanlı Ö, Dursun E. Cephalometric Evaluation of Class III Malocclusion Cases with Different Vertical Facial Development. ENT Updates 2020;10(2): 350-355. 